\title{
PERCEIVED DENTALANXIETY AMONG SCHOOLCHILDREN TREATED THROUGH THREE CARIES REMOVAL APPROACHES
}

\author{
Asli TOPALOGLU-AK ${ }^{1}$, Ece EDEN ${ }^{2}$, Jo E. FRENCKEN ${ }^{3}$
}

\author{
1- DDS, PhD. Lecturer, Department of Pediatric Dentistry, Ege University, School of Dentistry, Izmir, Turkey. \\ 2- DDS, PhD. Professor, Department of Pediatric Dentistry, Ege University, School of Dentistry, Izmir, Turkey. \\ 3- DDS. MSc, PhD. Assoc Professor, WHO Collaborating Centre for Oral Health Care Planning and Future Scenarios, Radboud University \\ Medical Centre, College of Dental Sciences, Nijmegen, the Netherlands. \\ Corresponding address: J.E. Frencken, WHO Collaborating Centre for Oral Health Care Planning and Future Scenarios, Radboud University \\ Medical Centre, College of Dental Sciences, P.O. Box 9101, 6500 HB Nijmegen, the Netherlands - Phone: $3124361-4050$ - fax: 3124 354- \\ 0265. \\ e-mail: j.frencken@dent.umcn.nl
}

Received: December 27, 2006 - Modification: May 22, 2007 - Accepted: June 11, 2007

\begin{abstract}
O bjectives: The aim of the investigation was to test the differences in the perceived level of dental anxiety among children treated restoratively using the Atraumatic Restorative Treatment (ART) approach, the traditional restorative (TRA) approach and ART aided with a chemomechanical caries removal gel (ART plus). Methods: The study subjects were 6-7-year-old children. TRA was compared to ART in a clinical setting after children had seen a dentist twice (Group A), ART was compared to 'ART plus' in a clinical setting after children had seen a dentist once (Group B) and ART was applied outside the clinic on school premises (Group C). The treatments were carried out in Class II cavitated dentine lesion in primary molars. Dental anxiety was measured using the Venham Picture Test (VPT). Three-way analysis of variances and interaction was applied to test for treatment approach, gender and operator effects on the mean VPT scores. Results: There was no statistically significant difference $(\mathrm{p}=0.80)$ observed between the mean VPT scores for the traditional approach and those for the ART approach and between ART with and without a chemomechanical caries removal gel ( $\mathrm{p}=0.07)$. Children in Group A had lower mean VPT scores than children in Group B $(\mathrm{p}=0.02)$ and Group C $(\mathrm{p}<0.00001)$ when treated using the ART approach by the same two operators. Conclusions: The level of dental anxiety was low. There was no difference in level of dental anxiety observed in children treated with ART in comparison to the traditional restorative approach, and between children treated with ART with and without a chemomechanical caries removal gel. The treatment environment and prepatory visits may be factors determining the level of dental anxiety in children treated through the ART approach only.
\end{abstract}

Uniterms: Dental anxiety; Atraumatic restorative treatment; Carisolv; Venham picture test

\section{INTRODUCTION}

The prevalence of dental caries has declined in many child populations in industrialized countries over the last three decades ${ }^{30}$. Despite this huge achievement, many child populations in both industrialized and less-industrialized countries have high levels of dental caries ${ }^{6,19}$. Furthermore, it is known that the percentage of unmet treatment needs in both primary and permanent teeth in children is high ${ }^{20,28}$. Several factors may contribute to the high percentage of these unmet treatment needs. One is believed to be the traditional way of treating cavitated dentine lesions, which is largely based on the use of rotary equipment that requires frequent administration of local anesthesia. Hence, both the bur and dental injection are considered the two main fear- provoking stimuli ${ }^{17,24}$. It is no surprise, therefore, that the use of traditional restorative treatment has a high potential for triggering dental anxiety in many children ${ }^{2,24}$ and that many children with dental anxiety refuse to undergo required dental recall visits ${ }^{14,15}$. This situation needs to be addressed.

Over the last decade, caries treatment approaches have been developed that appear to be less anxiety provoking for children than the traditional restorative approach. These new approaches include Atraumatic Restorative Treatment $(\mathrm{ART})^{9}$ and use of a chemomechanical caries removing gel ${ }^{8}$. These new treatment approaches follow the concept of minimal intervention dentistry ${ }^{26}$. The ART approach uses hand instruments only and hardly requires the use of local anesthesia, whereas the chemomechanical treatment approach uses rotary instruments and local anesthesia 
occasionally ${ }^{16}$.

The level of discomfort experienced during treatment of single- and multiple-surfaces cavitated dentine lesions in primary molars according to the ART approach in comparison to the traditional treatment approach has been studied. When the modified Venham Scale and heart rate were used as outcome variables, children treated through ART experienced less discomfort than age-mates treated through the traditional approach in a field situation ${ }^{23,27}$. Similarly, use of a chemomechanical caries removal gel (Carisolv ${ }^{\mathrm{TM}}$, Mediteam) was well accepted by children with dental anxiety ${ }^{1}$.

There have been no reports on the level of dental anxiety in children treated through ART and in those treated through ART aided with a chemomechanical caries removal gel in a dental clinic as compared to in the field. Neither has there been a study carried out comparing dental anxiety in children treated through ART and the traditional approach in a modern dental clinic. Therefore, the null hypotheses of this study were that there is no difference in the perceived level of dental anxiety among children treated restoratively in primary molars in a modern dental clinic between the ART approach and 1) the traditional approach and 2) ART aided with a chemomechanical caries removal gel. The last aim was to assess dental anxiety in children treated using the ART approach at school premises.

\section{MATERIALAND METHODS}

\section{Study Design and Subject Selection}

The present investigation is a compilation of three studies carried out independently from each other at different periods in time. The first study concerned a randomized clinical trial in which the traditional restorative treatment approach was compared to the ART approach in a dental clinic (Group A ${ }^{7}$. The second study was a randomized clinical trial in which the carious-tissue-removing effect of a chemomechanical gel in relation to the ART approach was compared to only ART in a dental clinic (Group B). The third study concerned an investigation in which the ART approach was applied on school premises (Group C).

The subjects in all three studies were 6-7-year-old children who had at least one Class II cavitated dentine lesion in a primary molar. The study populations of the substudies were selected from the same 17 elementary schools located in the vicinity of the Dental School. Screening for Class II cavitated dentine lesions was carried out by trained dentists from the Pediatric Department of the Dental School on school premises in daylight with the aid of a mouth mirror and probe. The only lesions to be included in the studies were Class II cavitated dentine lesions that had an opening wide enough for the ART excavator $(\varnothing=0.9 \mathrm{~mm})$ to penetrate and that had no pulpal involvement.

Group A included 160 children that were treated by 3 operators at the dental clinic of the Pediatric Department. In Group B, 4 operators at the same dental clinic treated 308 children. In Group C, 2 operators on their school premises treated 50 children. These last two operators also participated in groups $\mathrm{A}$ and $\mathrm{B}$.

Ethical approval to conduct the sub-studies was obtained from the ethical committee on human studies at Ege University in Izmir, Turkey (03-11/7M-599). An informed consent letter was given to each of the subjects. Only subjects who returned the letter signed by their parents or guardians were included in the study.

\section{Preparatory visits and treatment environment}

None of the included children had visited a dentist before. After they had been screened in their classrooms, selected children of Groups A and B together with their parents or guardians were invited to the dental clinic at the Pediatric Department. At their first visit to the dental clinic, which was their second meeting with dentists and dental staff, full intra-oral and radiographic examinations were carried out in order to ensure absence of pulp inflammation of the selected teeth after screening. In Group A, children were treated on appointment about two weeks after their first visit to the Pediatric Department. The children in Group $B$ were treated immediately after intra-oral and radiographic examination. The children in Group C were treated on school premises within 2 weeks after they had been screened for Class II cavitated dentine lesions. These children were not informed about the exact date of treatment.

All treatment procedures were performed without the presence of a parent or a guardian in the treatment room. Children that had to be excluded from the study were referred to the public dental clinic closest to their school.

\section{Description of caries management approaches}

The treatment procedures used in Group A have been described in detail ${ }^{7}$. A brief description of all treatment approaches is given below.

Traditional treatment procedure: The traditional treatment procedure consisted of removing carious tooth tissue using a micro-motor and hand piece with diamond and steel burs. The cavity was prepared following the minimal intervention concept. A saliva suction device and cotton wool rolls were used to isolate the tooth. No local anesthesia was administered. An Omni-matrix ${ }^{\mathrm{TM}}$ (Ultradent Products, Inc.) and interdental wooden wedges were used to prepare the cavity for restoration. A self-etch adhesive was applied according to the manufacturers' instructions. The preparations were restored with a composite resin material, which was cured using a halogen-light curing device. After bite adjustment, the restoration was polished using extra-fine diamond finishing burs and alumina-oxide containing discs.

The ART procedure: The ART treatment procedure consisted of widening a small cavity opening and/or removing thin enamel in larger cavity openings with a dental hatchet, until the enamel was free of visible demineralizations and access to the cavity was established. Soft infected dentine was excavated from the cavity walls and floor with spoon excavators. A suction device and cotton wool rolls were used to isolate the tooth in Group B, whereas cotton 
wool rolls only were used to isolate the tooth in Group C. No local anesthesia was administered. The preparations were restored with a composite resin and light-cured with a LED light source. The restoration was polished and bite adjusted using polishing strips.

ART in combination with a chemomechanical caries removal gel: The chemomechanical caries removal gel $\left(\right.$ Carisolv $^{\mathrm{TM}}$ ) was applied on carious dentine for 30 seconds after the cavity had been accessed by hand instruments. The softened dentine was scraped away using the specially designed Carisolv ${ }^{\mathrm{TM}}$ hand instruments. Excess Carisolv ${ }^{\mathrm{TM}}$ gel was removed with wet cotton wool pellets. Application of Carisolv $^{\mathrm{TM}}$ gel continued until the gel stayed clear. The prepared cavities were restored and finished in the same way as described for the ART procedure.

\section{Assessment of dental anxiety}

The children's level of anxiety was assessed using the Venham Picture Test (VPT) ${ }^{29}$. VPT is an anxiety assessment instrument that consists of 8 pictures representing feelings ranging from anxiety to contentment. In all three Groups, the operating dentist showed the pictures to the children at the end of the treatment session. The children were asked to select the picture that described their feelings when they were undergoing treatment. The sum of responses that represented negative feelings was recorded and ranged from 0 (not anxious at all) to 8 (extremely anxious) for each child.

Children of the ART and the chemomechanical caries removal gel group were also asked to rate the level of taste and smell of the gel, using the following options: a) I like it; b) I dislike it; c) I don't mind it. The sum of the options determined the acceptance level of the taste and smell of the gel.

\section{Statistical Analysis}

The analysis was carried out by a biostatistician at the College of Dental Sciences in Nijmegen, the Netherlands, using SPSS-12. A3-way analysis of variance and interaction was applied to test the effect of treatment procedure, gender and operator on the mean VPT scores. A two-sided significance level of 0.05 was used. The t-test was applied to test for differences between dependent and independent variables.

\section{RESULTS}

\section{Disposition of subjects}

The study population consisted of a total of 160 children (79 boys and 81 girls) in Group A, 308 children (157 boys and 151 girls) in Group B and 50 children (26 boys and 24 girls) in Group C. Their mean age was $7.0(\mathrm{SD}=0.3$ ) years. The children had neither systemic health problems nor mental disorders.

\section{Dental anxiety status}

Group A: The mean Venham Picture Test scores and standard deviations for the use of traditional and ART

approaches by operators are presented in Table 1 . No statistically significant difference $(\mathrm{p}=0.80)$ was observed between the mean VPT scores for the traditional approach and those for the ART approach. Neither a gender effect ( $p=0.34)$ nor an operator effect $(p=0.66)$ was observed for the mean VPT scores.

Group B: The mean VPT scores and standard deviations for the use of the ART approach in combination with and without a chemomechanical caries removal gel by operators are presented in Table 2 . No statistically significant difference $(\mathrm{p}=0.07)$ was observed between the mean VPT scores for the use of ART with and without a chemomechanical caries removal gel. However, an operator effect was observed. The mean VPT scores for operator 4 were statistically significantly $(\mathrm{p}=0.002)$ higher than those for the three other operators. Girls treated through ART in combination with a chemomechanical caries removal gel had higher mean VPT scores ( $\mathrm{p}=0.01$ ) than boys.

No gender effect was observed in the acceptance of smell ( $\mathrm{p}=0.50)$ and taste $(\mathrm{p}=0.86)$ of the gel in children treated through ART in combination with a chemomechanical caries removal gel. The level of smell and taste acceptance of the chemomechanical caries removal gel had a statistically

TABLE 1- The mean Venham Picture Test (VPT) scores and standard deviations for the use of the traditional and the ART approach by operators

\begin{tabular}{lcccc}
\hline & \multicolumn{2}{c}{$\begin{array}{c}\text { ART } \\
\text { Approach } \\
\text { Operator }\end{array}$} & $\mathbf{N}$ & \multicolumn{2}{c}{$\begin{array}{l}\text { Traditional } \\
\text { Approach }\end{array}$} \\
& & & $\mathbf{N}$ & $\begin{array}{c}\text { Mean } \pm \text { SD } \\
\text { Mean }\end{array}$ \\
\hline 1 & 25 & $0.8 \pm 1.6$ & 18 & $0.7 \pm 1.4$ \\
2 & 31 & $1.0 \pm 1.7$ & 24 & $1.1 \pm 2.0$ \\
3 & 40 & $1.0 \pm 1.7$ & 22 & $1.1 \pm 1.4$ \\
Total & 96 & $1.0 \pm 1.7$ & 64 & $1.0 \pm 1.6$ \\
\hline
\end{tabular}

TABLE 2- The mean Venham Picture Test (VPT) scores and standard deviations for the use of the ART approach with and without a chemomechanical caries removal gel by operators

ART

Approach

\begin{tabular}{lllll} 
Operator & $\mathbf{N}$ & Mean \pm SD & $\mathbf{N}$ & $\begin{array}{l}\text { Mel } \\
\text { Mean } \pm \text { SD }\end{array}$ \\
\hline 1 & 34 & $1.6 \pm 1.9$ & 31 & $0.7 \pm 1.2$ \\
2 & 36 & $1.5 \pm 1.6$ & 32 & $1.4 \pm 1.8$ \\
4 & 33 & $2.6 \pm 2.2$ & 36 & $1.8 \pm 1.8$ \\
5 & 55 & $1.2 \pm 1.7$ & 51 & $1.3 \pm 1.9$ \\
Total & 158 & $1.7 \pm 1.9^{\mathrm{a}}$ & 150 & $1.3 \pm 1.7^{\mathrm{b}}$ \\
\hline
\end{tabular}

a, b $p=0.07$ 
significant effect on the mean VPT scores. Children who reported that the smell or taste of the chemomechanical caries removal gel was unacceptable had higher mean VPT scores than children who did accept the smell or taste $(\mathrm{p}=0.006)$ (Table 3).

Group C: The mean VPT scores and standard deviation for the use of the ART approach on school premises for operators 1 and 2 were $2.1 \pm 1.6$ and $3.0 \pm 1.9$, respectively, which difference were not statistically significant (Mann Whitney U test; $\mathrm{p}=0.10$ ).

The mean VPT scores and standard deviations for the use of the ART approach for operators 1 and 2 in the three independent studies are presented in Table 4. Children in Group A had lower mean VPT scores than children in Group $\mathrm{B}(\mathrm{p}=0.02)$ and Group $\mathrm{C}(\mathrm{p}<0.00001)$.

\section{DISCUSSION}

Both null hypotheses were accepted. There is no difference in the level of dental anxiety in young children after treatment with ART and with the traditional restorative approach, and after treatment with ART with and without a chemomechanical caries removal gel in a dental clinic. The latter outcome was expected, as both treatment approaches are considered to be child-friendly, but the former outcome was a surprise.

The use of different evaluation tests to assess dental anxiety often makes comparison of results of studies impossible. In the present study, the VPT was used in order to overcome verbal-cognitive performance difficulty in

TABLE 3- The mean Venham Picture Test (VPT) scores and standard deviations for the use of the ART approach in combination with a chemomechanical caries removal gel according to acceptance of smell and taste of the gel

\begin{tabular}{lll} 
Acceptance of smell/taste & $\mathbf{N}$ & VPT \pm S.D. \\
\hline Yes & 116 & $1.1 \pm 1.6^{\mathrm{a}}$ \\
No & 34 & $2.0 \pm 1.9^{\mathrm{b}}$ \\
Total & 150 & $1.3 \pm 1.7$ \\
\hline
\end{tabular}

$\mathrm{N}=$ Number of children; ${ }^{\mathrm{a}, \mathrm{b}} \mathrm{p}=0.006$

TABLE 4- The mean Venham Picture Test (VPT) scores and standard deviations for the use of the ART approach for operators 1 and 2 by study

Study Mean VPT \pm SD

$\begin{array}{ll}\text { Group A } & 0.9 \pm 1.7^{\mathrm{a}} \\ \text { Group B } & 1.6 \pm 1.8^{\mathrm{b}} \\ \text { Group C } & 2.6 \pm 1.8^{\mathrm{c}}\end{array}$

a, b $p=0.02 ;{ }^{a, c} p<0.00001 ;{ }^{b, c} p=0.002$ young children. In addition, the test was easy to use and was easily integrated into the ongoing clinical activities and research design of the main clinical study ${ }^{7}$. However, there were some limitations with respect to the use of the VPT in the evaluation process of the present study. Firstly, the VPT was administered after treatment. Evaluating dental anxiety at that point in time may have disallowed children to express their feelings of anxiety at a particular moment during treatment. Furthermore, the children may have felt relaxed after treatment and, therefore, have rated the treatment procedure more positively than they actually felt. We have noticed instances in which children cried during the treatment procedure, without this being reflected in their choice of pictures. Secondly, only one test was applied to evaluate the psychological aspect of dental anxiety. However, as discomfort is a multidimensional construct, consisting of behavioral, cognitive and physiological aspects, it would have been ideally to carry out an additional test but that may have obstructed the continuity of the restorative treatment procedure in these young children.

Recently, dental anxiety among children treated with ART has been assessed using a combination of two tests: a modified Venham Scale and measuring the heart rate ${ }^{23,27}$. The study from Indonesia, carried out amongst 7-year olds (average age), reported generally less discomfort during treatment using the ART approach than using the traditional amalgam approach. The Indonesia study showed a statistically significant difference in comfort experienced between the ART and the traditional approach with the modified Venham Scale, and only in deep excavation when the heart rate was used. The same two evaluation measurements were also used to assess dental anxiety amongst on average 7-year olds in Surinam. The study outcome was different than that from the Indonesian study. The ART approach caused statistically significant less discomfort than the traditional approach when the modified Venham Scale was applied but not when the heart rate was used. It appears that the results of the heart rate and those of the modified Venham Scale do not correlate significantly. The findings from the two studies, referred to above, differ from those observed in the present Group A. where the use of the Venham Picture Test did not show a difference in dental anxiety between the two treatment approaches under study. Whether the subjective evaluation method administered by the modified Venham Scale used in the Indonesian and the Surinam studies (a dentist assessed the anxiety), that differs from the self expressive nature of the Venham Picture Test used in the present Group A (the children themselves assessed the anxiety), should be considered a reason for the difference in results obtained is not unreal but difficult to say.

The type of operator could be another reason for the difference in outcomes observed between the 3 studies. In Indonesia, the operators included dental students, whereas pedodontists performed the treatments in Surinam and in the present investigation. However, a clear pattern between experienced (pedodontists) and inexperienced (dental students) operators being absent, it seems that the level of 
specialist training should not be considered an explanatory variable.

The mean VPT scores in all 3 sub-studies of the present investigation were low. Unfortunately, neither the Indonesian study nor the Surinam one reported the magnitude of the dental anxiety scores observed in the children of the two treatment groups, rendering a comparison of the level of dental anxiety measured among the 3 studies impossible.

Two studies had been carried out in a dental clinic (Groups $\mathrm{A}$ and $\mathrm{B}$ ) and one in a school environment (Group C). Using the mean VPT scores for the two operators that had participated in all 3 studies, it appears that the children treated through ART in the school environment were more anxious than age mates treated in the clinic. Whether the location of the treatment is an explanatory factor is difficult to say. It may well be possible that the factor location is confounded by the extra examination visit to the clinic by children in Group A and $\mathrm{B}$, acclimatizing them to the environment and staff, before undergoing treatment. Such a visit may be important as is shown for children that needed to be treated using the traditional approach ${ }^{18,25}$.

Although the majority of children in the present investigation found the taste and smell of the chemomechanical caries removal gel acceptable, which is in line with findings in other studies ${ }^{8,11}$, those who did not like the taste and smell had higher levels of dental anxiety than those who did like it. Apparently, the acceptance of taste and smell of the chemomechanical caries removal gel is not uniform in all communities and affects the level of comfort felt during treatment.

The literature is equivocal with respect to whether girls have higher levels of dental anxiety than boys ${ }^{13,22}$. A gender effect was not observed in any of the sub-studies (Groups A, $\mathrm{B}$ and $\mathrm{C}$ ) in the present investigation, which is in agreement with results of studies reported elsewhere ${ }^{5}$. However, the present sub-study (Group B) showed that girls treated with a chemomechanical caries removal gel by one of the operators showed higher dental anxiety scores than girls treated by the other operators. This operator effect could be attributed to the fact that coping strategies and technical skills may vary among operators. Several studies have indicated that the behaviors of the dentist during treatment may play an important role in the development of dental fear or anxiety ${ }^{3,4,21}$.

Today, clinicians and researchers are aiming to understand and optimize children's responses to dental treatments. However, we are still uncertain about the etiological factors and their interaction with dental anxiety. A number of childfriendly treatment approaches have been promoted, but there is still a lot to be achieved. On the basis of the multi-factorial characteristics of dental anxiety, it must be stressed that, in addition to developing minimal invasive dentistry procedures, regular dental attendance and acquaintance with dental staff and dental environment are vital in reducing levels of dental anxiety in children. Therefore, children must be introduced to dentists and dental staff at an early age if we want to promote life-long good oral health into adulthood.

\section{CONCLUSIONS}

We conclude that the level of dental anxiety amongst these 7-year-old children was low. There was no difference in levels of dental anxiety observed in children treated with ART in comparison to the traditional restorative approach, and to those treated with ART and a chemomechanical caries removal gel. The use of VPT only may not have been sufficient to assess the level of anxiety in these children adequately. The lowest mean VPT scores for the ART approach only were obtained by children who had visited the dental clinic prior to being treated, and who were accompanied by their parents or guardians when they were treated on appointment in the clinic.

\section{ACKNOWLEDGEMENTS}

The authors wish to thank Dr. O. Oncag, Dr. O. Pamuk and Dr. A. Ozen for their contribution to the implementation of the study and Dr. B. van 't Hof for analyzing the data.

\section{REFERENCES}

1- Ansari G, Beeley JA, Fung DE. Chemomechanical caries removal in primary teeth in a group of anxious children. J Oral Rehabil. 2003;30:773-9.

2- Bergius M, Breggren U, Bogdanov O, Hakeberg M. Dental anxiety among adolescents in St. Petersburg, Russia. Eur J Oral Sci. 1997;105:117-22.

3- Corah NL, O'Shea RM, Ayer WA. Dentists' management of patients' fear and anxiety. J Am Dent Assoc. 1985;110:734-6.

4- Corah NL, O’Shea RM, Bissell GD, Thines TJ, Mendola P. The dentist-patient relationship: perceived dentist behaviors that reduce patient anxiety and increase satisfaction. J Am Dent Assoc. 1988;116:73-6.

5- Corkey B, Freeman R. Predictors of dental anxiety in six-year-old children: findings from a pilot study. J Dent Child. 1994;61:267-71.

6- Cote S, Geltman P, Nunn M, Lituri K, Henshaw M, Garcia RI. Dental caries of refugee children compared with US children. Pediatrics. 2004;114:733-40.

7- Eden E, Topaloglu-Ak A, Frencken JE, van 't Hof MA. Survival of self-etch adhesive Class II composite restorations using ART and conventional cavity preparations in deciduous molars. Am J Dent. In 2006;19:359-63.

8- Ericson D, Zimmerman M, Raber H, Gotrick B, Bornstein R, Thorell J. Clinical evaluation of efficacy and safety of a new method for chemo-mechanical removal of caries. Caries Res. 1999;33:1717.

9- Frencken JE, Pilot T, Songpaisan Y, Pantumvanit P. Atraumatic Restorative Treatment (ART): rationale, technique and development. J Public Health Dent. 1996;56:135-40.

10- Frencken JE, Makoni F, Sithole WD, Hackenitz E. Three-year survival of one-surface ART restorations and glass-ionomer sealants in a school oral health programme in Zimbabwe. Caries Res. 1998;32:119-26. 
11- Fure S, Lingström P. Evaluation of the chemomechanical removal of dentine caries in vivo with a new modified Carisolv gel. Clin Oral Investig. 2004;8:139-44.

12- Holmgren CJ, Lo ECM, Hu DY, Wan HC. ART restorations and sealants placed in Chinese school children: results after three years. Community Dent Oral Epidemiol. 2000;28:314-20.

13- Klingberg G, Berggren U, Noren JG. Dental fear in an urban Swedish child population: prevalence and concomitant factors. Community Dent Health. 1994;11:208-14.

14- Kruger E, Thomson WM, Poulton R, Davies S, Brown RH, Silva PA. Dental caries and changes in dental anxiety in late adolescence. Community Dent Oral Epidemiol. 1998;26:355-9.

15- Kvale G, Berggren U, Milgrom P. Dental fear in adults: a metaanalysis of behavioral interventions. Community Dent Oral Epidemiol. 2004;32:250-64.

16- Maragakis GM, Hahn P, Hellwig E. Chemomechanical caries removal: a comprehensive review of the literature. Int Dent J. 2001;51:291-9.

17- Milgrom P, Coldwell SE, Getz T, Weinstein P, Ramsay DS. Four dimensions of fear of dental injections. J Am Dent Assoc. 1997;128:756-62.

18- Milsom KM, Tickle M, Humphris GM, Blinkhorn AS. The relationship between anxiety and dental treatment experience in 5year-old children. Br Dent J. 2003;194:503-6.

19- Mouradian WE, Wehr E, Crall JJ. Disparities in children's oral health and access to dental care. JAMA. 2000;284:2625-31.

20 - Pitts NB, Boyles J, Nugent ZJ, Thomas N, Pine CM. The denta caries experience of 5-year-old children in England and Wales (2003/ 4 ) and in Scotland (2002/3). Surveys co-ordinated by the British Association for the Study of Community Dentistry in 2001/2002. Community Dent Health. 2005;22:46-56.

21 - Prins P, Veerkamp J, ter Horst G, de Jong A, Tan L. Behavior of dentists and child patients during treatment. Community Dent Oral Epidemiol. 1987;15:253-7.

22- Raadal M, Milgrom P, Weinstein L, Manel L, Cauce AM. The prevalence of dental anxiety in children from low-income families and its relationship to personality traits. J Dent Res. 1995;74:143943

23- Schriks MCM, van Amerongen WE. Atraumatic perspective of ART. Psychological and physiological aspects of treatment with and without rotary instruments. Community Dent Oral Epidemiol. 2003;31:15-20

24- Ten Berge M, Hoogstraten J, Veerkamp JS, Prins GJ. The dental subscale of the children's fear survey schedule: a factor analytic study in the Netherlands. Community Dent Oral Epidemiol. 1998;26:340-

25- Tickle M, Williams MJ, Jenner AM, Blinkhorn A. The effects of socioeconomic status and dental attendance on dental caries' experience, and treatment patterns in 5-year-old children. $\mathrm{Br}$ Dent $\mathrm{J}$. 1999;186:135-7.

26- Tyas MJ, Anusavice KJ, Frencken JE, Mount GJ. Minimal intervention dentistry: a review. FDI commission project 1-97. Int Dent J. 2000;50:1-12.

27- Van Bochove JA, van Amerongen WE. The influence of restorative treatment approaches and the use of local analgesia, on the children's discomfort. Eur Arch Paediatr Dent. 2006;7:11-6.
28- Van Wijk PJ, van Wijk C. Oral health in South Africa. Int Dent J. 2004;54:373-7.

29- Venham LL, Bengston D, Cipes M. Children's response to sequential dental visits. J Dent Res. 1977;56:454-9.

30- Whelton H. Overview of the impact of changing global patterns of dental caries experience on caries clinical trials. J Dent Res. 2004;83(sp. issue C):C29-34. 